\title{
On the feasibility of re-stimulation of shale wells
}

\author{
Mohammad O. Eshkalak ${ }^{1} \cdot$ Umut Aybar $^{1} \cdot$ Kamy Sepehrnoori $^{1}$
}

Received: 13 August 2014/Published online: 8 July 2015

(C) The Author(s) 2015. This article is published with open access at Springerlink.com

\begin{abstract}
As a result of advances in horizontal completions and multi-stage hydraulic fracturing, the U.S. has been able to economically develop several decades of worth of natural gas. However, a considerable concern has risen on the economic viability of shale gas development for reasons associated with the fast production declines as well as recent down-turns of natural gas prices besides rises in the costs of new technologies. Therefore, an economic analysis is required to investigate the profitability of the refracturing treatment of unconventional gas resources. Net present value of cash flows and internal rate of return are calculated for a range of gas prices considering 20 years of natural gas production from a typical unconventional shale gas reservoir. A systematic comparison is then accomplished for three scenarios: (1) re-fracturing versus no refracturing, (2) combination of re-fracturing and drilling new wells, and (3) time-dependent re-fracturing treatment. Further, this paper incorporates the cost of re-fracturing treatment, the cost of drilling a new horizontal well, the water treatment cost, as well as the current and future price of natural gas in the model. The findings of this work would help the future re-stimulation development plans of the emerging unconventional shale gas plays.
\end{abstract}

Keywords Economic analysis - Unconventional shale assets · Hydraulic re-fracturing · Net present value . Internal rate of return

Mohammad O. Eshkalak

eshkalak@utexas.edu

1 The University of Texas at Austin - PGE, 200 E Dean Keeton, Austin, TX 78712, USA

Edited by Xiu-Qin Zhu

\author{
Abbreviations \\ SRR Source rock reservoir \\ NPV Net present value \\ IRR Internal rate of return \\ LRE Long-term re-fracturing efficiency \\ D\&C Drilling and completion \\ EUR Estimated ultimate recovery \\ FC Fixed costs \\ $V_{\mathrm{F}} \quad$ Future value of production revenue for a \\ fracture reservoir, $\$$ \\ $V_{0} \quad$ Future value of production revenue for an \\ un-fractured reservoir, \$ \\ $i \quad$ Interest rate \\ $C_{\text {Well }} \quad$ Cost of one horizontal well, \$

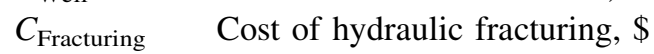 \\ $C_{\text {Re-fracturing }}$ Cost of re-fracturing, $\$$ \\ $N \quad$ Number of horizontal wells, $\$$ \\ MSCF $10^{3}$ standard cubic feet, $\mathrm{ft}^{3}$ \\ BCF $10^{6}$ standard cubic feet, $\mathrm{ft}^{3}$
}

\section{Introduction}

A substantial fraction of United States natural gas production for the next decades is surmised to be supported by unconventional resources, such as shale gas plays. Large accumulations of gas shale tight formations serve as both a hydrocarbon source and a productive reservoir. Most of the gas is stored in organic-rich rock, while a lesser portion of gas in place is in pore spaces (Cipolla et al. 2010). Also, 500-1000 Tcf of potential natural gas reserve is estimated to be in place in unconventional assets (Arthur 2008). Extremely low matrix permeability 
as well as highly complex networks of natural fractures are unique characteristics of shale formations. Permeability of shale rocks is estimated to be between $50 \mathrm{nD}$ (nano-Darcy) to $150 \mathrm{nD}$ (Javadpour et al. 2007). Recent advances and innovations in hydraulic fracturing are key to the success of shale gas economic production as a viable global energy supply.

Shale gas reservoirs have some unique attributes which make hydraulic fracturing a viable option for natural gas production. Unlike conventional gas reservoirs, insufficient permeability, the ultra-low porosity of shale rock, and the limited reservoir contact, but the widespread organic matter in shale, cannot offer production in a commercial quantity without stimulation processes. Development of shale resources is still in its early stages and most wells are at the early stage of their working lifetime. Moreover, reservoir simulations and modeling of unconventional reservoirs has gained much attention in the recent years. Many studies have been conducted from the shale pore scale up to reservoir scales to improve the understanding of flow behavior in complex shale formations. Among them, researchers such as Brown et al. (2009), Cipolla et al. (2010), Moghanloo and Javadpour (2014), Omidvar Eshkalak (2013), Aybar et al. (2014a, b, c, 2015), and Eshkalak et al. (2013, 2014a, b, c, d, f) have developed and discussed numerical, quasi-static, analytical and semi-analytical reservoir models for unconventional reservoirs.

The combination of advances in hydraulic fracturing and horizontal drilling has led to the acceptance of these techniques for enhancing the production from shale strata since their first commercial implementation. Nevertheless, drilling so many horizontal wells to increase the production has not been a solution to the economic success of the shale development projects. Additionally, a recent decline in natural gas price has led to a huge shrinkage of shale gas development projects in the U.S. and operators have reduced their rig counts in these unconventional basins. Therefore, a comprehensively engineered economic model is necessary for the processes that boost natural gas production from depleted wells, which also in turn, guides decision-making processes for operators in their current development plans.

\section{Re-fracturing treatment of shale gas wells}

When production rates drop below economic limits, significant amounts of producible reserves still remain in the existing stimulated reservoir volume. In general, shale gas wells usually show a sharp decline at the beginning due to free gas production (existing in natural fractures or pore spaces around the wellbore) which is captured through a long transient liner flow. As a result, re-fracturing is often considered as the best option for increasing production from unconventional gas reservoirs to an economic level. Nevertheless, the re-fracturing treatment of shale wells is still in its infancy where the applicability of the technology has not yet been proven and the conditions under which it may be successful are not clearly understood for long-term profitability of shale reservoirs. Jayakumar et al. (2013) discussed that re-fracturing can be applied to shale fields because of two reasons. First, the original fracturing network has no significant contribution to the flow to the wellbore and second, the initial completion performance has degraded over time below operational or economic limits.

There are publications that address different aspects of re-fracturing treatments. For Barnett shale, Siebrits et al. (2000) reported increased production of natural gas by refracturing treatment. On the selection of candidate wells and time of re-fracturing treatment, researchers such as Craig and Blasingame (2005), Rousell and Sharma (2011), Moore and Ramakrishnan (2006), and Tavassoli et al. (2013) discussed and have developed criterion-based approaches. Moreover, the success of a re-fracturing treatment depends on the depleted reservoir pressure and hydraulic fracture geometry (Vincent 2010; Shekar and Hariharan 2011; Wang et al. 2013). We suggest that consideration should be given from the beginning to determine the best way to accomplish a re-fracturing treatment when the primary production has declined to a predetermined point.

Furthermore, the re-fracturing treatment is considered more beneficial because of two reasons: (1) it can be an alternative of new well drilling, and potentially can save around 1-4 million dollars (Alison and Parker 2014); and (2) the environmental impact of reusing a wellbore is dramatically less than drilling and completing a new well in a different location. However, uncertainties, associated with outcome of re-fracturing and the economic analysis of key parameters influencing its profitability, are still challenging, and need wider investigation and systematic studies. Hence, preventing a non-economic development of re-fracturing necessitates an economic analysis of the refracturing treatment.

There are three main challenges in re-fracturing treatment of shale gas wells, namely the selection of candidate wells, determination of optimal re-fracturing time, and the placement of new fractures. A robust procedure introduced by Tavassoli et al. (2013) is employed in this study, with which all the wells are considered to be good candidates satisfying their criteria. Further, the re-fracturing treatment is applied after 5 years of production as an optimal refracturing time. Also, Tavassoli et al. (2013) found that natural gas production achieved its maximum value by 
placing the hydraulic re-fractures in the middle of each pair of primary hydraulic fractures. Figure 1 shows the effect of re-fracturing placement between each pair of the primary hydraulic fractures.

An economic evaluation is systematically performed to determine the net present value (NPV) of the re-fracturing treatment for a typical unconventional shale gas reservoir in this paper through incorporating the cost of re-fracturing treatment, cost of drilling a new horizontal well, water treatment cost, as well as the current and future price of natural gas.

\section{Methodology of economic evaluation}

While advancements in horizontal drilling and hydraulic fracturing have made the extraction of natural gas from shale formations feasible and the significant production decline of unconventional well requires a method of enhancing recovery, it is still questionable if the re-fracturing is advantageous or not. Therefore, an economic analysis is performed to unfold the economic viability of the unconventional reservoirs. The net present value (NPV) of the cash flows and internal rate of return (IRR) are calculated for the given scenarios in this paper. Profitability is gauged based on whether the values are positive or negative for the resulting NPV calculations and if the IRR values are greater than the minimum acceptable rate of return of $10 \%$ (Duman 2012).

An unconventional gas field was chosen for the economic evaluation. This field consists of 50 horizontal wells with an average horizontal length of $4000 \mathrm{ft}$. NPV of cash flows and IRR are calculated for different assumed gas prices given 20 years of natural gas production predictions from a typical unconventional reservoir. A systematic comparison is made for three scenarios given below. These

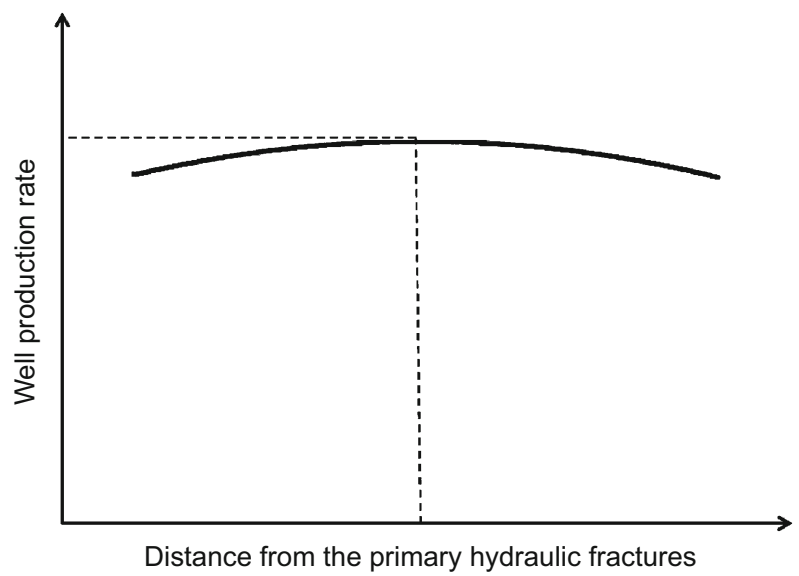

Fig. 1 The effect of re-fracturing placement on well production scenarios are compared with the base case scenario without re-fracturing treatment of the wells. These scenarios are chosen to help show the effects of production decline and different timeframes of the production on overall profitability of a typical shale field:

(1) Re-fracturing treatment of all the wells after specific years of production.

(2) Re-fracturing and drilling new wells after specific years of production.

(3) Time-dependent re-fracturing treatments.

In order to determine the economic feasibility, a cash flow model is constructed first and the NPV and IRR are calculated for all the three scenarios. In the cash flow model, capital expenses are defined as the sum of all the costs. The cost of fracture and re-fracture treatment per stage depends on the fracture half-length, which in this study, an average of $750 \mathrm{ft}$ is employed. All the cost values are general average values based on the personal communication with different operators accomplished by Schweitzer and Bilgesu (2009). Table 1 shows the approximate expenses associated with the development of a horizontal gas well. It should be noted that in all the scenarios, the same values are used for the economic results.

We assume that candidate wells for re-fracturing treatment are already selected; in this study, all 50 wells are candidate wells and also the hydraulic re-fractures are placed in the middle of each pair of old hydraulic fractures as it can maximize the production, and also the candidate selection and treatment execution steps are relatively straightforward according to Tavassoli et al. (2013). The economic analysis is performed based on 20 years of predicted gas production. Also, three different gas prices, 4, 5 , and 6 dollars per Mscf (thousand standard cubic feet) are considered in the model. The cash flow statements are constructed based on the above assumptions and consequently NPV and IRR are calculated in order to determine the overall profitability of the wells.

Determining the cumulative natural gas production for 20 years is potentially the most critical component of the economic analysis. Acquiring field production rates within a shale asset is difficult since these data are proprietary company information. However, the expected ultimate recovery (EUR) approximations as well as initial rates of production for different shale formations are available widely through the literature. Several decline curve analyses methods are developed for unconventional resources that may not be accurate for unconventional reservoirs due to complexities and uncertainties associated with the shale gas reservoirs compared to the conventional gas reservoirs. Hence, the available production data and production predicted through several runs with an in-house reservoir 
Table 1 Costs used in economic model

\begin{tabular}{ll}
\hline Parameter & Value \\
\hline Well cost & 0.5, million dollars/1000 ft \\
Re-frac. cost & 100, thousand dollars/stage \\
Operating costs & 300, thousand dollars/year \\
Gas price & $4,5,6$, dollars/Mscf \\
Interest rate & $10 \%$ \\
Royalty tax & $15 \%$ \\
Water management cost & $10 \%$ of total fixed costs \\
\hline
\end{tabular}

simulator are analyzed and the results are used for the NPV and IRR calculation. Increased production by the re-fracturing treatment is incorporated into the analysis by considering the long-term re-fracturing efficiency (LRE) introduced by Tavassoli et al. (2013). LRE is assumed equal to 1.3 for all the 50 wells in this study. Table 2 represents the cumulative natural gas production in $\mathrm{BCF}$ (billion cubic feet) for all the three scenarios.

Table 2 demonstrates that re-fracturing in scenario 1 after 10 years of primary production will enhance the cumulative gas production by $34 \mathrm{BCF}$. Also, for scenario 2, the production is increased almost twice as much as that in scenario 1 , as the wells in scenario 2 has been re-fractured in every 5 years instead of 10 years. Scenario 3 demonstrates that by conducting re-fracturing treatment and drilling new wells, the cumulative production is increased more than that in scenario 2, but one should consider that the economic viability of scenario 3 is of concern due to high costs associated to drilling new horizontal wells.

Several cost components and assumptions are used in the economic calculation and cash flow calculations that are explained below. Items $1-5$ give a detailed explanation of each component of the assumptions below.

\subsection{Lease acquisition and royalty costs}

The money paid to land owners for lease acquisition and royalties represents a significant amount of the required capital; ignoring this section in the analysis will result in a false sense of overall profitability of a shale natural gas field. An average lease acquisition cost of $\$ 3500$ per acre is assumed in this study. An average of $15 \%$ royalty rate per gross revenue is considered for NPV calculations.

\subsection{Site preparation and permitting fees}

These expenses are introduced in addition to part 1 that is associated with the preparation of the drilling site and the permit fees required for drilling a well. However, since in unconventional resources, several wells are drilled from a pad so this expense is calculated once in NPV calculations. For 50 wells, we assumed 10 pads including 5 wells in each. This cost is roughly estimated about $\$ 400,000$ for each pad.

\subsection{Drilling and completion costs (D\&C costs)}

The first part (i.e., the drilling cost) is the expenses incurred related to the drilling of a horizontal well and the second part is the expenses related to the steps taken to prepare a well for production. This aspect consists primarily of stimulation activities such as hydraulic fracturing and refracturing along with casing and cementing costs. Average D\&C cost of 5 million dollars are assumed for a typical shale gas well (\$0.5 million per $1000 \mathrm{ft}$ ).

\subsection{Operating costs}

Additional costs are associated with the day-to-day production of natural gas. These costs consist of labor, repairs and maintenance, materials and supply as well as

Table 2 Cumulative production for different scenarios

\begin{tabular}{lllll}
\hline Years of primary production (years) & \multicolumn{2}{l}{ Cumulative production for different scenarios, BCF } \\
\cline { 2 - 5 } & No re-fracturing & (1) Re-fracturing & $\begin{array}{l}\text { (2) Re-fracturing } \\
\text { in 5 year intervals }\end{array}$ & $\begin{array}{l}\text { (3) Re-fracturing plus drilling ten new } \\
\text { wells at year 10 }\end{array}$ \\
\hline 10 & 150 & 150 & 160 & 160 \\
20 & 200 & 234 & 262 & 287 \\
\hline
\end{tabular}




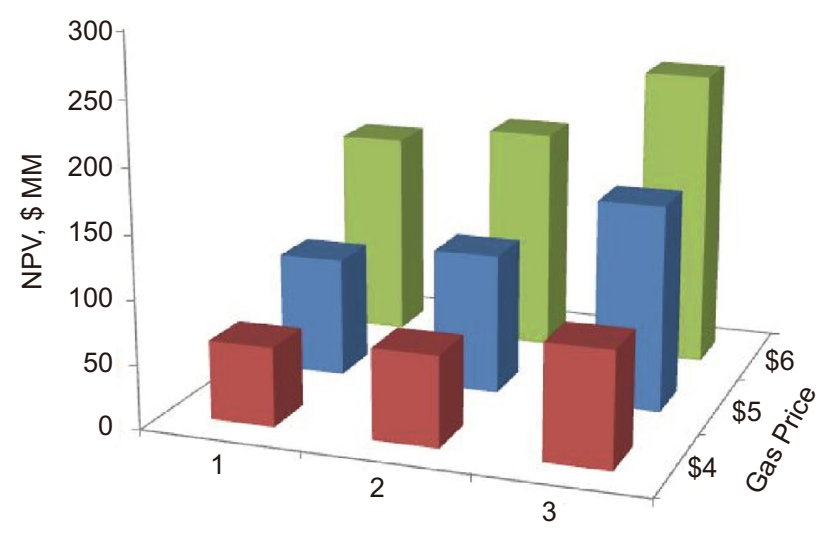

Fig. 2 Calculated NPV for 20 years for three scenarios with three different gas prices

administration costs. They represent re-occurring annual cash costs incurred throughout the economic life of a well. The value of $\$ 1$ per Mscf is assumed and considered constant for the entire life of all wells $(\$ 300,000$ per year assuming $0.3 \mathrm{BCF}$ gas produced per year per well).

\subsection{State and federal corporate income taxes}

The state and federal taxes as additional expenses are accounted into the cash flow statement. A state tax of $10 \%$ and federal income tax of $35 \%$ are considered in this study.

The general approaches for calculating NPV and IRR are based on the theories reported by Newman (1988) and Ikoku (1985). The NPV formula is given in Eq. 1:

$$
\begin{aligned}
\mathrm{NPV}= & \sum_{j=1}^{n} \frac{\left(V_{\mathrm{F}}\right)_{j}}{(1+i)^{j}}-\sum_{j=1}^{n} \frac{\left(V_{0}\right)_{j}}{(1+i)^{j}} \\
& -\left[\mathrm{FC}+\sum_{k=1}^{N}\left(C_{\text {well }}+C_{\text {Fracturing }}+C_{\mathrm{Re} \text {-fracturing }}\right)\right],
\end{aligned}
$$

where $V_{\mathrm{F}}$ is the future value of production revenue for a fracture reservoir, $V_{\mathrm{O}}$ is the future value of production revenue for an un-fractured reservoir, $i$ is the interest rate, FC is the total fixed cost, $C_{\text {well }}$ is the cost of one horizontal well, $C_{\text {fracture }}$ and $C_{\text {re-fracture }}$ are the cost of hydraulic fracturing and re-fracturing in a horizontal well, respectively, and $N$ is the number of horizontal wells.

\section{Results and analysis}

The goal of this paper was to evaluate the profitability of the re-fracturing treatment of a typical shale gas reservoir. This economic evaluation is performed based on NPV and IRR calculations considering cash flow assumptions discussed above. Several calculations are completed in order to determine the profitability of each scenario incorporating different gas prices. The NPV is calculated for each scenario considering a discount rate of $10 \%$, which has been accepted as a minimum acceptable rate of return in the natural gas industry (MIT Energy Initiative, 2010). All the calculated NPVs greater than zero are considered profitable.

Figure 2 shows the calculated NPV for all the three scenarios performed with the assumptions of three different gas prices. As it demonstrates, NPV values are positive for all the three scenarios, showing the profitability of the refracturing treatment as a method for enhancing the gas recovery and the overall economy of a typical shale gas asset with $\mathbf{5 0}$ horizontal gas wells. With a slight rise in gas price, the NPV increases rapidly. This fast turnover also results in a fast development of new wells drilled in unconventional gas fields aside from re-fracturing old wells.

The calculation of IRR of the cash flow is performed after NPV is calculated. This IRR represents the interest rate that yields an NPV for the cash flow equivalent to zero. All the IRRs are considered profitable for the values above $10 \%$. Table 3 shows the IRR calculated for each scenario. These values are acceptable since they are greater than $10 \%$ (MIT Energy Initiative 2010) and show that scenarios studied in this paper are profitable given the assumptions made based on the predictions for 20 years of production. It is demonstrated that with a little change in gas price, the $I R R$ is raised. In this study, 3rd scenario is the most profitable one, which shows that drilling a new well must be considered in the long-term development planning of shale gas reservoirs.

Table 3 Internal rate of return (IRR)

\begin{tabular}{lllll}
\hline Gas price & \multicolumn{2}{l}{ IRR for different scenarios, $\%$} & \\
\cline { 2 - 5 } & No re-fracturing & (1) Re-fracturing & $\begin{array}{l}\text { (2) Re-fracturing } \\
\text { in 5 years intervals }\end{array}$ & $\begin{array}{l}\text { (3) Re-fracturing plus drilling 10 new } \\
\text { wells at year 10 }\end{array}$ \\
\hline$\$ 4$ & 15 & 18 & 22 & 24 \\
$\$ 5$ & 35 & 38 & 43 & 49 \\
$\$ 6$ & 50 & 54 & 61 & 65 \\
\hline
\end{tabular}




\section{Conclusions}

This study provides an assessment of the importance of refracturing treatment of shale gas wells. This analysis allows us to predict the future pace of the re-fracturing treatment activity which also helps the large-scale economic planning of unconventional resources within the U.S. Results of the three scenarios are as follows:

(1) The calculated $N P V$ for all three scenarios are positive; this demonstrates the profitability of the refracturing treatment considering today's gas price of $\$ 4$.

(2) NPV is almost doubled with the increase in the gas price considering the third scenario. This shows that a slight raise in the natural gas price will make a huge jump in the development plans of unconventional shale gas.

(3) The highest $N P V$ is gained when the combination of re-fracturing and new well drilling is planned. This scenario is recommended for the future development plans once the gas price rises from $\$ 4$ to $\$ 6$.

(4) It is also recommended that in order to have a higher level of $I R R$, more new horizontal wells must be drilled considering a constant gas price of $\$ 4$.

(5) According to the economic assumptions used in this study, the re-fracturing treatment of shale gas wells is demonstrated to play an important role in the economic success of an unconventional asset.

Given these conclusions, the re-fracturing treatment of shale horizontal wells with properly identified candidates not only recoups the overall economic recovery of shale wells but also makes a profit. Moreover, pertinent information must be gathered along with an economic analysis before the treatment commences.

Open Access This article is distributed under the terms of the Creative Commons Attribution 4.0 International License (http://creativecommons.org/licenses/by/4.0/), which permits unrestricted use, distribution, and reproduction in any medium, provided you give appropriate credit to the original author(s) and the source, provide a link to the Creative Commons license, and indicate if changes were made.

\section{References}

Alison D, Parker M. Re-fracturing extends lives of unconventional reservoirs. The American Oil and Gas Reporter, Exploration/ Drilling/Production History, 2014

Arthur, JD. Hydraulic fracture for natural gas well of the Marcellus Shale, The ground water production council 2008 annual forum. Cincinnati; 2008.

Aybar U, Eshkalak MO, Sepehrnoori K, et al. Long term effect of natural fractures closure on gas production from unconventional reservoirs. Paper SPE 171010 presented in SPE Eastern Regional Meeting 2014 held in Charleston, West Virginia. 21-23 Oct 2014a.
Aybar U, Eshkalak MO, Sepehrnoori K, et al. The effect of natural fracture's closure on long-term gas production from unconventional resources. J Nat Gas Sci Eng. 2014;. doi:10.1016/j.jngse. 2014.09.030.

Aybar U, Yu W, Eshkalak MO, et al. Evaluation of production losses from unconventional shale reservoirs. J Nat Gas Sci Eng. 2015;23:509-16.

Aybar U. Investigation of analytical models incorporating geomechanical effects on production performance of hydraulically and naturally fractured unconventional reservoirs. MSc Thesis. The University of Texas at Austin, Austin, 2014c.

Brown M, Ozkan E, Raghavan R, et al. Practical solutions for pressure transient responses of fractured horizontal wells in unconventional reservoirs. Paper SPE 125043 presented at the SPE ATCE, New Orleans, LA. 4-7 Oct, 2009.

Cipolla CL, Lolon EP, Erdle JC, et al. Reservoir modeling in shalegas reservoirs. SPE Reserv Eval Eng. 2010;13(4):638-53 SPE 125530-PA.

Craig DP, Blasingame T. A new refracture candidate diagnostic test determines reservoir properties and identifies existing conductive or damaged fracture. Paper SPE 96785 presented at annual technical conference and exhibition, Dallas. 9-12 Oct 2005.

Duman RJ. Economic viability of shale gas production in the marcellus shale; indicating by production rates, cost and current natural gas price. MS thesis, Applied Natural Resources Economics, Michigan Technology Institute, 2012.

Eshkalak MO, Al-Shalabi EW, et al. Enhanced gas recovery by $\mathrm{CO}_{2}$ sequestration versus re-fracturing treatment in unconventional shale gas reservoirs. Paper SPE 172083 presented at 2014 Abu Dhabi international petroleum and exhibition and conference held in Abu Dhabi, UAE, 10-13 Nov 2014a.

Eshkalak MO, Al-Shalabi EW, et al. Simulation study on the $\mathrm{CO}_{2-}$ driven enhanced gas recovery with sequestration versus the refracturing treatment of horizontal wells in the U.S. unconventional shale reservoirs. J Nat Gas Sci Eng. 2014a;. doi:10.1016/j. jngse.2014.10.013.

Eshkalak MO, Aybar U, Sepehrnoori K. An economic evaluation on the re-fracturing treatment of the U.S. shale gas resources. Paper SPE 171009 presented at the 2014 SPE eastern regional meeting held in Charleston. 21-23 Oct 2014c.

Eshkalak MO, Aybar U, Sepehrnoori K. An integrated reservoir model for unconventional resources, coupling pressure dependent phenomena. Paper SPE 171008 presented at the 2014SPE eastern regional meeting held in Charleston. 21-23 Oct 2014 d.

Eshkalak MO, Mohaghegh SD, Esmaili S. Synthetic, geomechanical logs for Marcellus Shale. Paper SPE 163690 presented at the 2013 SPE digital energy conference and exhibition held in Woodlands. 5-7 Mar 2013.

Eshkalak MO, Mohaghegh SD, Esmaili S. Geomechanical properties of unconventional shale reservoirs. J Pet Eng. 2014b;. doi:10. $1155 / 2014 / 961641$.

Ikoku CU. Economic analysis and investment decisions. New York: Wiley; 1985.

Javadpour F, Fisher D, Unsworth M. Nanoscale gas flow in shale gas sediments. J Can Pet Technol. 2007. PETSOC-07-10-06.

Jayakumar R, Boulis A, Aura Araque-Martinez A. Systematic study for re-fracturing modeling under different scenarios in shale reservoirs. Paper SPE 165677 presented at the 2013 SPE eastern regional meeting held in Pittsburgh. 20-22 Aug 2013.

MIT Energy Initiative. The future of natural gas: an interdisciplinary MIT study interim report. Cambridge: Massachusetts Institute of Technology; 2010.

Moghanloo RG, Javadpour F. Applying method of characteristics to determine pressure distribution in 1D shale-gas samples. SPE J. 2014;19(03):361-72. doi:10.2118/168218-PA. 
Moore LP, Ramakrishnan H. Restimulation: candidate selection methodologies and treatment optimization. SPE paper presented at 2006 annual technical conference and exhibition, San Antonio. 24-27 Sept 2006.

Newman DG. Engineering economic analysis. 3rd ed. Salt Lake: Engineering Press, Inc; 1988.

Omidvar Eshkalak M. Synthetic geomechanical logs and distributions for Marcellus Shale. MSc Thesis. 2013. Morgantown: West Virginia University.

Rousell N, Sharma M. Refracture reorientation enhances gas production in barnett shale tight gas well. Paper SPE 134491 presented at the 2011 SPE annual technical conference and exhibition, Denver. 30 Oct-2 Nov 2011.

Schweitzer R, Bilgesu HI. The role of economics on well and fracture design completions of Marcellus Shale wells. Paper SPE 157532 presented at 2009 eastern regional meeting held in Charleston. 23-25 Sept 2009.

Shekar S, Hariharan R. A novel screening method for selection of horizontal refracturing cadidates in shale gas reservoirs. Paper
SPE 134032 presented at the 2011 North American unconventional gas conference and exhibition, The Woodlands. 14-16 June 2011.

Siebrits E, Elbel JL, et al. Refracture reorientation enhances gas production in barnett shale tight gas well. Paper SPE 63030 presented at the 2000 SPE annual technical conference and exhibition, Dallas. 1-4 Oct 2000.

Tavassoli S, Yu W, Javadpour F, et al. Well screen and optimal time of re-fracturing: a barnett shale well. J Pet Eng. 2013; doi:10. 1155/2013/817293.

Vincent MC. Restimulation of unconventional reservoirs: when are refracs beneficial. Paper SPE 136757 presented at the 2010 Canadian unconventional resources and international petroleum conference, Calgary. 19-21 Oct 2010.

Wang SY, Luo XL, Hurt, RS. What we learned from a study of refracturing in Barnett Shale: an investigation of completion/ fracturing, and production of refractured wells. Paper IPTC 17081 presented at the 2013 international petroleum technology conference, Beijing. 